\title{
Estudo observacional dos riscos ambientais em laboratório de pesquisa em Recife/PE
}

\author{
Observational study of environmental risks in research laboratory in Recife/PE \\ Estudio observacional de riesgos ambientales en laboratorio de investigación en \\ Recife/PE
}

Julianna Carolina da Silva Vicente ${ }^{1}$, Daivyane Aline Mota da Rocha², Fernanda Cristina Gomes de Lima $^{1}$, Heloisa Fernanda Augusto ${ }^{3}$, Everton Morais da Silva ${ }^{1}$, Julianne Damiana da Silva Vicente, José Ancelmo da Silva Cintra Júnior ${ }^{5}$, Jorge Belém Oliveira Júnior ${ }^{1,6 *}$.

\section{RESUMO}

Objetivo: Realizar um estudo observacional sobre os riscos ambientais e as práticas de biossegurança por profissionais e estudantes na rotina diária de um laboratório de pesquisa em Recife/PE. Métodos: Trata-se de uma pesquisa descritiva com abordagem observacional, a qual foi realizada através da verificação e caracterização da rotina laboratorial dos usuários, averiguação da utilização de equipamentos de proteção, identificação dos riscos ambientais e elaboração de mapa de risco. Resultados: Foram constatados alguns riscos ambientais, principalmente o risco biológico (33\%), seguido do risco de acidentes (27\%), enquanto o risco físico foi o menos encontrado (7\%). Nossos dados demonstraram que existem riscos ambientais de determinadas intensidades no ambiente laboratorial. O laboratório de pesquisa foi classificado como Nível de Biossegurança 2 (NB 2), pois há desenvolvimento de atividades com agentes biológicos da classe de risco 2, ou seja, aqueles que podem acarretar risco individual moderado e risco coletivo baixo. Conclusão: Sendo assim, conclui-se que através da execução de práticas de Biossegurança, tanto os pesquisadores, quanto os usuários de laboratórios, além da disponibilidade do mapa de risco, podem melhorar suas condutas frente aos riscos ambientais, garantindo uma melhor qualidade da saúde dos profissionais e dos trabalhos desenvolvidos.

Palavras-chave: Biossegurança, Laboratório de pesquisa, Risco ambiental, Mapa de risco.

\section{ABSTRACT}

Objective: To realize an observational study of environmental risks and biosafety practices by professionals and students in the daily routine of a research laboratory in Recife/PE. Methods: It is a descriptive research with an observational approach, which was realized through the verification and characterization of the users' laboratory routine, investigation of use of protective equipment, identification of environmental risks and elaboration of risk map. Results: Some environmental risks were found, mainly biological risk (33\%), followed by accident risk (27\%), while physical risk was the least found $(7 \%)$. Our data demonstrated that there are environmental risks of certain intensities in the laboratory environment. The research laboratory was classified as biosafety level 2 (BL-2), as there is development of activities with biological agents of risk class 2, that is, those that can cause moderate individual risk and low collective risk. Conclusion: Thus, it is concluded that through the implementation of biosafety practices, both researchers and laboratory users, in addition to the availability of the risk map, can improve their conduct in face of environmental risks, ensuring a better quality of health for professionals and the work developed.

Keywords: Biosafety, Research lab, Environmental risks, Risk map.

\footnotetext{
1 Universidade Federal de Pernambuco (UFPE), Recife - PE. *E-mail: junniorbiologia@hotmail.com

2 Instituto Aggeu Magalhães - FIOCRUZ/PE, Recife - PE.

3 Universidade de São Paulo (USP), São Paulo - SP.

${ }^{4}$ Universidade de Pernambuco (UPE), Recife - PE.

${ }^{5}$ Universidade Federal Rural de Pernambuco (UFPE), Recife - PE.

${ }^{6}$ Centro Universitário Maurício de Nassau (Uninassau), Recife - PE.
} 


\section{RESUMEN}

Objetivo: Realizar un estudio observacional de los riesgos ambientales y las prácticas de bioseguridad por investigadores y estudiantes en la rutina diaria de un laboratorio de investigación en Recife/PE. Métodos: Se trata de una investigación descriptiva con enfoque observacional, que se llevó a cabo mediante la verificación y caracterización de la rutina de laboratorio, investigación del uso de equipos de protección, identificación de riesgos ambientales y elaboración de mapa de riesgos. Resultados: Se encontraron riesgos ambientales, principalmente el biológico (33\%), seguido del riesgo de accidentes (27\%), mientras que el riesgo físico fue el menos encontrado (7\%). Nuestros datos demostraron que existen riesgos ambientales de intensidad en el entorno del laboratorio. El laboratorio de investigación fue clasificado como Nivel de Bioseguridad 2, ya que se están desarrollando actividades con agentes biológicos de clase de riesgo 2, es decir, aquellos que pueden ocasionar riesgo individual moderado y riesgo colectivo bajo. Conclusión: Así, se concluye que, a través de la implementación de prácticas de Bioseguridad, tanto los investigadores como los usuarios del laboratorio, además de la disponibilidad del mapa de riesgos, pueden mejorar su conducta ante los riesgos ambientales, asegurando una mejor calidad de salud para los profesionales y el trabajo desarrollado.

Palabras clave: Bioseguridad, Laboratorio de investigación, Riesgos ambientales, Mapa de riesgos.

\section{INTRODUÇÃO}

Os laboratórios de pesquisa normalmente estão vinculados a uma instituição de ensino, sendo frequentados por diversos profissionais, sendo considerados um ambiente sem perigos aparentes (ARAÚJO EM e VASCONCELOS SD, 2004; FARIA VA, et al., 2011). Esses locais podem proporcionar o desenvolvimento de projetos de pesquisas, além de procedimentos que estão em frequente modernização, visto o surgimento de novas técnicas laboratoriais. Por tais fatores podem ocorrer acidentes ou eventuais riscos, seja devido à falta de atenção e comportamento dos usuários, que por muitas vezes se esquecem de aplicar a biossegurança, ou até o desconhecimento, como a não concepção que determinada atividade que pode gerar diversos riscos (FRANKLIN SL, et al., 2009; COLACO GA, et al., 2015).

Os riscos ambientais encontrados nos laboratórios de pesquisa podem ocasionar agravos à saúde dos frequentadores, principalmente pelo contato direto com materiais biológicos, como: sangue, líquidos e tecidos potencialmente infectantes; ou substâncias nocivas (ácidos, compostos tóxicos e substâncias cancerígenas), e também equipamentos (AZEVEDO NA, et al., 2016).

Neste contexto, os acidentes ou riscos devem ser avaliados em todas as circunstâncias habituais e não habituais, com o intuito de evitá-los. Inúmeras atividades são realizadas, como exemplo a pesquisa de agentes desconhecidos ou pouco descritos na literatura, os quais podem gerar possíveis riscos, até então inexploráveis, aos manipuladores, o que assegura a importância das práticas de biossegurança (FARIA VA, et al., 2011).

A biossegurança é composta por medidas protetivas ao indivíduo e ao coletivo que asseguram a integridade do manipulador. Estas medidas tentam minimizar a exposição do indivíduo a determinados riscos ambientais através de ações de bloqueio, práticas de controle e educação continuada desses profissionais, buscando alcançar conscientização e discernimento para o quesito de saúde e segurança ocupacional (HINRICHSEN SL, 2004).

Entre as importantes medidas de segurança, o mapa de risco é utilizado como esquema de prevenção de acidentes e doenças de trabalho e, assim, programado para melhorias nas condições trabalhistas (HINRICHSEN SL, 2018). É considerado uma configuração gráfica para identificar os riscos (biológicos, químicos, físicos, ergonômicos e de acidentes) e suas intensidades nos locais de trabalho, buscando minimizar os riscos ambientais.

Sendo assim, o laboratório de pesquisa possui diversas fontes de riscos ambientais, contendo suas peculiaridades e níveis de ameaças. Desse modo, o presente estudo teve por objetivo analisar a execução de práticas de biossegurança em um laboratório de pesquisa no Recife/PE, com a finalidade de reconhecer os riscos nesse ambiente e evitá-los nas práticas de rotina, garantindo a qualidade na saúde do profissional. 


\section{MÉTODOS}

\section{Tipo de pesquisa}

Trata-se de uma pesquisa descritiva e observacional, sem intervenção no curso natural ou no desfecho da rotina. A coleta de dados foi realizada através de uma lista de verificação com descrição dos pontos traçados a serem observados, sendo relacionados aos riscos ambientais e às práticas de biossegurança.

\section{Local de estudo}

O estudo foi realizado em um laboratório de pesquisa básica, localizado em instituição pública de ensino superior na cidade de Recife/Pernambuco/Brasil, após a apresentação dos objetivos do estudo e da autorização dos profissionais responsáveis. Como solicitado pelos responsáveis, não haverá divulgação do local ou nome de terceiros.

\section{Instrumentos de coleta de dados}

Todas as descrições dos equipamentos observados e do espaço físico do laboratório de pesquisa foram descritas em uma planilha. Além disso, foi desenvolvida uma lista de verificação com o objetivo de facilitar a captação de dados e realização da análise observacional da presença ou ausência dos diversos tipos de riscos ambientais.

\section{Análise dos dados}

Os resultados foram avaliados e descritos por análise estatística (média e porcentagem) com adição dos dados no software Microsoft Excel 2010. Em seguida, foram gerados gráficos e tabelas para melhor apreciação dos resultados.

\section{RESULTADOS E DISCUSSÃO}

\section{Características gerais do laboratório}

O laboratório de pesquisa é composto por 22 usuários: 1 técnico, 2 pesquisadores, 1 pós-doutorado, 1 estagiário e 17 bolsistas. Estes bolsistas se enquadram em alunos de iniciação científica, mestrandos e doutorandos. O fluxo dos usuários neste ambiente é determinado através de um cronograma, de acordo com as atividades a serem realizadas. Este laboratório é considerado de médio porte, situado no primeiro andar de uma instituição de pesquisa, no qual possui diversos equipamentos para uso coletivo e dispostos para sua utilização correta (Quadro 1 e Figura 1).

Quadro 1 - Equipamentos presentes no laboratório de pesquisa observado e utilizados na rotina.

\begin{tabular}{|c|c|}
\hline Equipamento & Utilização \\
\hline Agitador & Destinado à agitação de soluções. \\
\hline Armário & $\begin{array}{l}\text { Armazenamento de produtos químicos, vidrarias, placas e materiais de } \\
\text { escritório }\end{array}$ \\
\hline Balança Analítica & Determinação de massas para soluções \\
\hline Banho-maria & Aquecimento de substâncias líquidas e sólidas \\
\hline $\begin{array}{c}\text { Cabine de Segurança } \\
\text { Biológica }\end{array}$ & Manipulação de agentes biológicos \\
\hline Calibrador & Calibração outros instrumentos \\
\hline Centrífuga & Separação de amostras \\
\hline Computador & Consultas acadêmicas \\
\hline Cuba de eletroforese & Realização da eletroforese \\
\hline Esterilizador & Esterilização \\
\hline Estufas & Incubação de meios de cultura e secagem e esterilização \\
\hline Freezer & Armazenamento de soluções \\
\hline Micro-ondas & Aquecimento de substâncias \\
\hline Microscópio óptico & Análise de microrganismos \\
\hline Pias & Uma para lavagem de objetos e a outra para lavagem de mãos \\
\hline Refrigerador & Armazenamento de soluções \\
\hline Transiluminador & Visualização de ácidos nucleicos separados por eletroforese \\
\hline
\end{tabular}

Fonte: Vicente JCS, et al., 2020. 
De acordo com a Instrução Normativa CTNBio nำ, o laboratório se enquadra no Nível de Biossegurança 2 (NB 2), pois há manipulação de agentes biológicos da classe de risco 2, ou seja, aqueles que podem acarretar risco individual moderado e risco coletivo baixo, sendo suas práticas divididas em: leishmaniose, esquistossomose, microbiologia e entomologia (BRASIL, 1997).

Desta forma, este laboratório deve respeitar determinadas regras e requisitos, alguns citados na Quadro 2, como: acesso restrito aos profissionais da área e aos estudantes que exerçam atividade relacionada ao ensino, pesquisa e extensão, com autorização do responsável técnico. Assim como, uma sala específica para guardar as bolsas e objetos pessoais e símbolo de risco biológico na entrada do laboratório (PENNA PMM, et al., 2010; SANGIONI LA, et al., 2013).

Figura 1 - Disposição dos equipamentos no laboratório de pesquisa analisado.

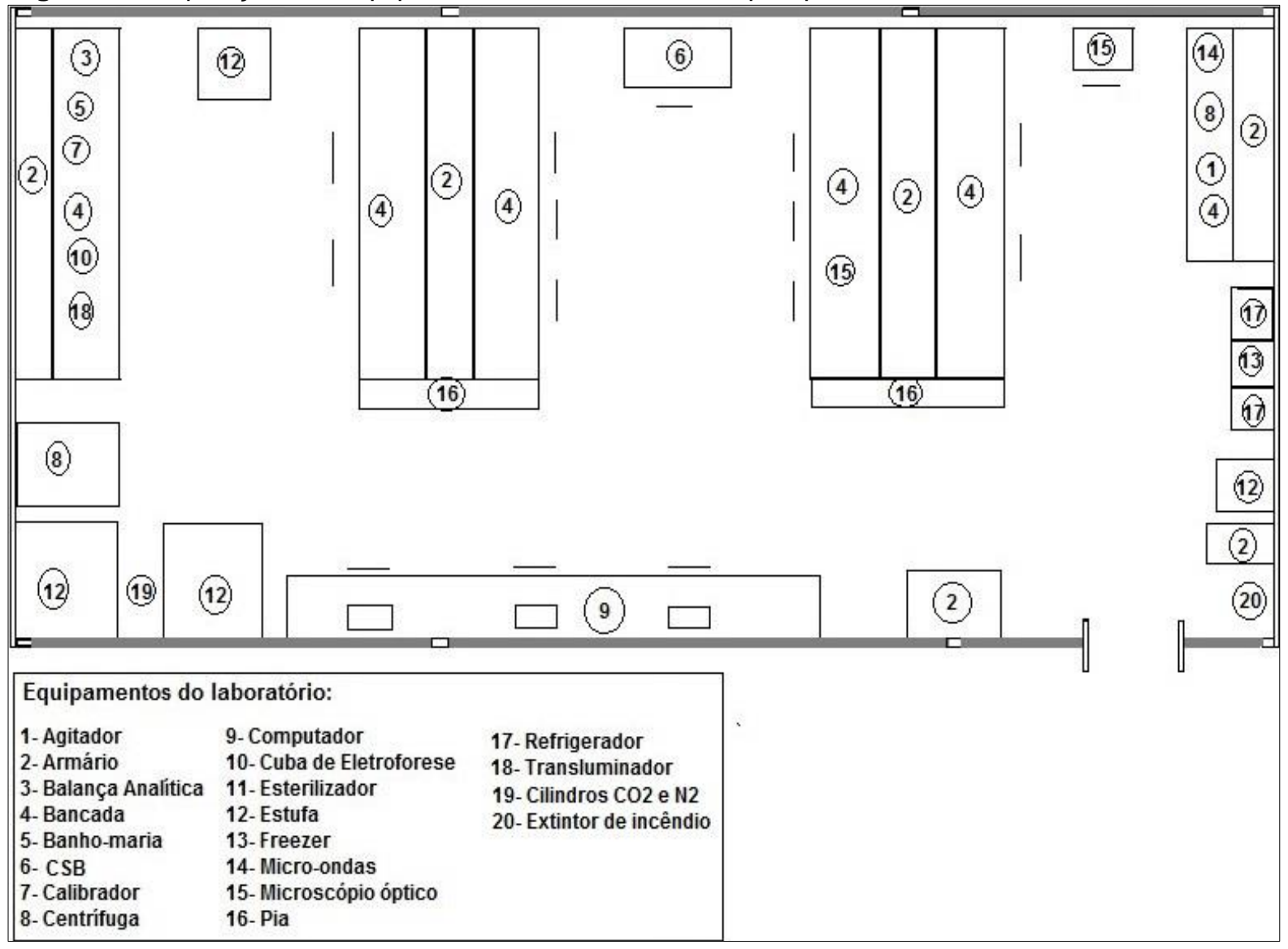

Fonte: Vicente JCS, et al., 2020.

Observou-se que o laboratório respeita esses requisitos. Na entrada encontra-se registrado o nome e telefones dos responsáveis e usuários do laboratório, bem como a sinalização para o uso de EPI's e aviso de restrição apenas para pessoas autorizadas. Os objetos pessoais e roupas são retidos em uma sala e não há consumo de alimentos e bebidas no ambiente e o uso do aparelho celular é permanentemente proibido. Contudo, não foi observado o símbolo do risco biológico, indicando os agentes manipulados e o nível de biossegurança, tanto na entrada do laboratório, como nas áreas de manipulação.

O piso do laboratório é adequado às condições necessárias ao trabalho, não apresentando elevações ou desníveis, possuindo resistência mecânica e química. As paredes são de cor clara, fosca, com resistência ao fogo e impermeáveis. Já o teto possui borrifadores, instalações de lâmpadas em número suficiente que atende à necessidade dos laboratoristas, com as luminárias embutidas, grelhas e as instalações elétricas estão corretas, não oferecendo riscos, correspondendo às condições exigidas pela NR-8 (BRASIL, 1978a). As bancadas existentes são do tipo "ilha" e "parede", e estão conformes com o tipo de uso, possuindo superfície lisa e impermeável, que permite o trabalho dos usuários do laboratório (BRASIL, 2004). 
Quadro 2 - Principais requisitos para um laboratório se enquadrar no nível 2 de segurança laboratorial.

\begin{tabular}{|c|c|}
\hline Requisitos & $\begin{array}{c}\text { Nível de } \\
\text { Biossegurança 2 }\end{array}$ \\
\hline Isolamento do laboratório & $\mathrm{N}$ \\
\hline Sala completamente vedada para descontaminação & $\mathrm{N}$ \\
\hline $\begin{array}{c}\text { Áreas de escritórios designados à administração e pesquisa fora das } \\
\text { instalações de biocontenção }\end{array}$ & $\mathrm{N}$ \\
\hline $\begin{array}{c}\text { Local para acondicionamento de roupas e objetos pessoais fora das } \\
\text { áreas de biocontenção }\end{array}$ & $\mathrm{S}$ \\
\hline Refeitório fora da área de biocontenção & $\mathrm{S}$ \\
\hline $\begin{array}{c}\text { Símbolo do risco biológico afixado na porta de entrada e nas áreas de } \\
\text { manipulação de agentes biológicos }\end{array}$ & $\mathrm{S}$ \\
\hline $\begin{array}{c}\text { Sistema para higienização e segurança: pias para lavagem de mãos com } \\
\text { acionamento mecânico ou automático e chuveiro e lava-olhos }\end{array}$ & $\mathrm{S}$ \\
\hline Adução do ar & $\mathrm{R}$ \\
\hline Sistema de ventilação controlada & $\mathrm{R}$ \\
\hline Entrada com porta dupla & $\mathrm{N}$ \\
\hline Sistema de portas com travamento mecânico ou automático & $\mathrm{R}$ \\
\hline Cabine de segurança biológica (CBS) classe II & $\mathrm{S}$ \\
\hline Uso de Equipamentos de Proteção lndividuais & $\mathrm{S}$ \\
\hline Cumprimento das Boas Práticas de Laboratórios & $\mathrm{S}$ \\
\hline
\end{tabular}

Legenda: N- Não mandatório; S- Uso é mandatório; R- uso é recomendável.

Fonte: Vicente JCS, et al., 2020. Adaptado de Sangioni LA, et al., 2013.

Existem duas pias, uma para lavagem de vidrarias e descartes e outra para lavagem de mãos, sendo confeccionadas com material resistente às substâncias nocivas, com profundidade ideal, além do que, ambas possuem acionamento com pedal, dispensando o contato com as mãos. Mesmo sendo em pontos próximos, não foi observado congestionamento para utilização ou bloqueio da circulação.

Para cada procedimento e equipamento presente no laboratório têm-se um Procedimento Operacional Padrão (POP), que se localiza em um livro de fácil acesso, disponível para ser consultado por quaisquer usuários. Segundo Barbosa CM, et al. (2011), a utilização do POP permite atingir a homogeneidade dos procedimentos a serem realizados.

\section{Lista de Verificação}

A lista de verificação consiste em um meio de avaliação de pontos a serem observados. Cada item dessa lista tem por objetivo despertar a atenção do analisador e evitar o esquecimento de algum item que deve ser averiguado (BARBOSA EF e MOURA DG, 2004).

Para avaliar os riscos ambientais, foi utilizada uma lista de verificação composta por 30 itens. Para elaboração foram considerados os dados obtidos através da revisão de literatura deste trabalho. Seu preenchimento foi através das opções "Sim" e "Não", e anotações observadas consideradas importantes. Desta maneira, foi possível pontuar os riscos ambientais mais evidentes no laboratório.

\section{Avaliação dos Riscos}

No laboratório foi observada manipulação de microrganismos patogênicos, como: bactérias (Pseudomonas aeruginosa, Acinetobacter baumannii, Staphylococcus aureus, Klebsiella pneumoniae, Escherichia coli), protozoários (Leishmania infantum e Trypanosoma cruzi), helmintos (Schistosoma mansoni) e vetores (mosquitos do gênero Aedes e Culex). Não foram observadas pesquisas com outros microrganismos (fungos e vírus).

Durante as visitas observacionais foi verificado o contato com estes microrganismos através de experimentos ou do descarte. Neste contexto, as principais fontes de risco biológico constatadas são as estufas bacteriológicas, nas quais são armazenadas as culturas microbianas; e a cabine de segurança biológica, utilizada para manipulação das culturas e realização de experimentos. Nesses locais não foi notado 
o símbolo de risco biológico para alertar o manipulador a ter os cuidados necessários. Além disso, não foi observado o uso de óculos de proteção, sendo este um dos EPl's necessários para a manipulação desses microrganismos, visto que, houve manipulação fora das cabines de segurança biológica. De acordo com Sangioni LA (2013), devem-se usar óculos de proteção para evitar que respingos advindos das culturas ou amostras biológicas atinjam os olhos, podendo causar irritação ou outras lesões.

Para cada trabalho desenvolvido, há descartes distintos por cores para cada grupo microbiano. A desinfecção destes materiais se dá mediante a adição de hipoclorito de sódio (5\%) por 24 horas. Em seguida, os materiais são descartados no lixo branco, o qual é recolhido diariamente por equipe especializada. Conforme Pereira PMM, et al. (2015), o hipoclorito de sódio é um bom agente desinfetante, visto que tem ampla ação microbicida e progressiva de acordo com o maior tempo de exposição e de concentração. Vale ressaltar que a superfície das bancadas era descontaminada com o auxílio de álcool a $70 \%$ e papel toalha, antes e após cada procedimento. Estudos apontam que o álcool a 70\% é um bom redutor microbiano em pelo menos 99.9\% (RODRIGUES JA, et al., 2016).

Quanto à higienização das mãos, foi observada sua realização antes e após cada experimento. Contudo, o laboratório não contém dispensador de sabão, e o papel para secagem das mãos não estava acondicionado em recipiente apropriado. O sabão líquido antisséptico estava disposto em um recipiente e o papel permanecia em sua embalagem de origem na bancada. Mesmo as torneiras possuindo acionamento automático, o fato de não ter dispensador de sabão atrapalha uma correta higienização das mãos. Conforme a Anvisa (2007), o ideal é ter dispensadores de sabão líquido de fácil esvaziamento e preenchimento, evitando assim a sua contaminação. Como também é recomendado o uso de refil, e ter porta-papel-toalha para evitar respingos advindos de água e sabão no papel.

Havia dispensador de álcool em gel, contudo, durante as visitas observacionais, neste não continha o refil. De acordo com Araújo AP, et al. (2015), o álcool em gel é uma substância bactericida altamente recomendada por não causar reações adversas na pele.

O laboratório continha duas lixeiras, destinadas aos descartes comum e infectante. Em relação ao descarte do lixo, foi observada uma não conformidade em relação ao descarte de luvas usadas, pois estas foram destinadas ao lixo comum. É muito importante que o descarte de resíduos químicos e biológicos seja realizado corretamente. Essa segregação deve acontecer assim que o resíduo for gerado, a fim de reduzir os riscos sanitários e facilitar ações seguras para ter um tratamento ideal (GOMES GCC, et al, 2014).

Os riscos físicos no laboratório estão presentes com maior ocorrência nos equipamentos. As principais fontes de temperatura elevada observadas foram estufa de secagem, banho-maria, aquecedor, agitador magnético, micro-ondas e esterilizador, enquanto os de temperatura baixa foram os freezers, geladeiras e condicionador de ar. No entanto, a temperatura não era extrema, mas ideal ao trabalho e aos procedimentos desenvolvidos, além de ideal aos equipamentos, os quais não produziam ruídos. Não foram observadas pressões anormais ou umidade no ambiente laboratorial, o que compete de acordo com a NR 9 (BRASIL, 1978b).

A única radiação presente é a ultravioleta (UV) da cabine de segurança biológica. Porém, não prejudica fisicamente os usuários do laboratório, visto que permanece ligada durante 15 minutos, blindada, antes e após cada trabalho realizado. Apesar disso, como não há uma sala específica para a cabine de segurança biológica, na qual o trabalhador permaneça na ausência da UV, é necessário o uso de EPIs (jaleco e protetores faciais). Deve-se evitar exposição prolongada à UV, pois esse tipo de radiação pode causar problemas à retina, e de forma cumulativa, pode causar queimaduras e até câncer de pele (VIEIRA RGL, et al., 2008; ROSA FCS, et al., 2012).

Em relação aos riscos químicos, o laboratório não continha capela de exaustão química, sendo este um dos EPC's recomendados para retirada de gases tóxicos e/ou corrosivos do ambiente (SILVA MDS, et al., 2015). A manipulação de produtos químicos era realizada em outro laboratório, considerado apropriado para essa atividade, evitando assim os riscos. A rotulagem dos produtos químicos estava correta, constando a classificação através de símbolos, de acordo com o perigo que o produto apresentava, e os produtos estavam na validade. Havia uma ficha de identificação de todas as substâncias químicas utilizadas no laboratório, disponível para consulta, de acordo com a NR 32 (BRASIL, 2005). 
Estes produtos eram organizados em armários. No entanto, foram observadas substâncias inflamáveis armazenadas em caixas abaixo do armário e da pia. É necessário que todos os produtos sejam armazenados em locais apropriados de acordo com sua categoria química e não dispostos no chão. Durante o estudo, foi observada a presença de álcool isopropílico. $O$ isopropanol em condições normais de armazenamento produz efeitos que não são considerados sérios. Entretanto, quando está armazenado incorretamente, além de ser inflamável e explosivo, pode causar irritação nos olhos, no nariz, na garganta e depressão do sistema nervoso central (VIEIRA RGL, et al., 2008; GOMES LC, et al., 2016).

No laboratório há também cilindros de dióxido de carbono $\left(\mathrm{CO}_{2}\right)$ e Nitrogênio $\left(\mathrm{N}_{2}\right)$, ambos localizados entre duas estufas, presos a correntes. Durante um trabalho que necessitava de congelamento criogênico, não foram utilizados os EPI's necessários como luvas e óculos de proteção. Os cilindros que contêm gases necessitam ser manipulados com cuidado, a fim de evitar quedas dos mesmos e vazamentos de gases (BRASIL, 2005; OLIVEIRA CMA, et al., 2007).

Quanto aos riscos de acidentes, foi notada uma quantidade de caixas de papelão em cima dos armários e embaixo deles, e mesmo que estas não estejam bloqueando a passagem, podem cair e causar algum acidente. Assim como, nas bancadas ficavam dispostos materiais que iriam ser utilizados em experimentos. Chaves MJF (2016) esclarece que se deve manter o laboratório sempre limpo e arrumado, evitando armazenar produtos e materiais que não são pertinentes ao trabalho.

O manuseio de perfurocortantes não costumava ser corriqueiro. Entretanto, havia uma caixa especifica para seu descarte e outra para as vidrarias quebradas. Esta é uma ação preventiva de acidentes, pois o descarte de perfurocortantes deve ser realizado em caixas apropriadas contendo paredes rígidas e tampas com identificação (PENNA PMM, et al., 2010).

No laboratório havia um kit de primeiros socorros. Contudo, considerado insuficiente, pois o mesmo não apresentava a quantidade de materiais necessária ao número de pessoas que o frequentam, como também faltavam alguns itens. Segundo Sangioni LA, et al. (2013), um kit de socorro imediato deve conter: bandagens pequenas, de tamanho médio e grande, esterilizadas para ferimentos nos dedos, mãos e pés, e outras partes do corpo, esparadrapo, algodão em número suficiente, vaselina esterilizada, $1000 \mathrm{~mL}$ de soro fisiológico e antídotos especiais para os produtos tóxicos usados no laboratório.

Todas as instalações elétricas estavam adequadas. Em todas as tomadas havia a sinalização através de figuras, de risco de choque elétrico, alertando os usuários do laboratório. O número de tomadas também estava de acordo com o número de equipamentos, evitando assim sobrecargas (ROSA FCS, et al., 2012). Há apenas uma porta de acesso, mas esta atende ao espaço do laboratório. As rotas de fuga, o corredor e as escadas são devidamente sinalizados. Assim como, há a presença de pontos de iluminação de emergência.

O uso de EPIs é obrigatório dentro do laboratório. Seu uso é alertado através de avisos por todo interior do ambiente, como também na região externa, precisamente na porta do laboratório. Esses materiais de proteção são fornecidos gratuitamente aos usuários. No entanto, não foi observado o uso de óculos, luvas especiais para determinados procedimentos, toucas e máscaras faciais. Quanto aos EPC's, há um extintor de incêndio, do tipo dióxido de carbono $\left(\mathrm{CO}_{2}\right)$ próximo à porta. Sendo um dos mais recomendados para laboratórios, pois é fácil de manejar, tem eficiência para combater o início de incêndios e não danifica os equipamentos (ROSA FCS, et al., 2012).

Não há chuveiro e lava-olhos dentro do laboratório. Estes equipamentos estão dispostos em um local de acesso favorável a todos os usuários da instituição. No entanto, o uso destes pode ser prejudicado, devido estarem dispostos distantes de locais que possam ocorrer acidentes. O chuveiro de emergência é utilizado para banhos em caso de acidentes com produtos químicos, biológicos e fogo, ele pode ser localizado próximo ao local de risco até uma distância de 15 metros. Já o lava-olhos deve ser utilizado em caso de respingos durante o contato com os riscos. Este dispositivo pode estar acoplado ou não ao chuveiro, mas deve estar presente em cada setor (BRASIL, 2012).

Durante as observações, foi notado em um dia de experimento que muitas pessoas estavam presentes em um corredor para realizar determinada atividade. Conforme Zochio LB (2009), o ideal seria o mínimo de pessoas para evitar assim dispersão da atividade, conversas paralelas e evitar acidentes. 
Em relação aos riscos ergonômicos, foi visto que as bancadas e as mesas fornecem uma visualização adequada ao trabalhador. Contudo, os assentos não proporcionam conforto, principalmente os que estão na cabine de segurança biológica e nos microscópios ópticos. Tal situação, não facilita o ajuste ideal à altura do usuário, e desta forma o encosto não consegue ser adaptado para a proteção da região lombar. A bancada dos computadores estava de acordo com as normas, mas na mesma não existia apoio para os pés. Este que deve existir e se adaptar ao comprimento da perna do trabalhador (BRASIL, 1978c).

Durante as visitas observacionais, duas lâmpadas não estavam funcionando, o que poderia prejudicar a iluminação em dois pontos no ambiente laboratorial e afetar o trabalho de alguns profissionais. Segundo a NR 17, a iluminação geral deve ser uniformemente distribuída, de modo que evite ofuscamento, reflexos incômodos, sombras e contrastes excessivos, evitando assim fadiga ocular (BRASIL, 1978c).

Os movimentos repetitivos foram notados através do uso de pipetas automáticas. A repetição é considerada um fator de risco, podendo ser minimizado por pausas bem distribuídas (FERREIRA VMV, et al., 2009). A má postura ao realizar determinadas atividades também pode acarretar futuras dores osteomusculares, e que podem ser evitadas com um simples treinamento e pausas para recuperação (KASSADA DS, et al., 2011).

Para os riscos psicossociais, como não foram aplicados questionários, sendo realizada apenas uma análise observacional, não há como afirmar o que cada usuário do laboratório considera como risco psicossocial. No entanto, durante a observação, concluiu-se que os riscos psicossociais giram em torno da exigência e estresse. Pois, como se trata de um laboratório de pesquisa, devem-se seguir cronogramas para a entrega de trabalhos e teses, e quando um experimento não se conclui, ou o prazo para a entrega está próximo, o nível de estresse e cobranças aumenta, assim como a intensidade do trabalho.

Segundo Veloso Neto H (2015), a presença dos riscos psicossociais pode refletir em danos ao trabalhador, aos equipamentos de trabalho e à sua organização. Como consequências mais comuns: irritação, cansaço, dificuldade de concentração, distúrbios do sono, angústia, agressividade, depressão, entre outros.

Sendo assim, durante a observação dos riscos ambientais foi possível constatar que o risco biológico é o mais provável de acontecer (33,3\%). Enquanto a ocorrência de riscos de acidentes seria $27 \%$, seguido pelos riscos ergonômicos (20\%), riscos físicos $(6,6 \%)$ e riscos químicos (13,3\%), como descritos no Gráfico 1.

Gráfico 1 - Porcentagem dos riscos ambientais observados durante o estudo observacional no laboratório de pesquisa.

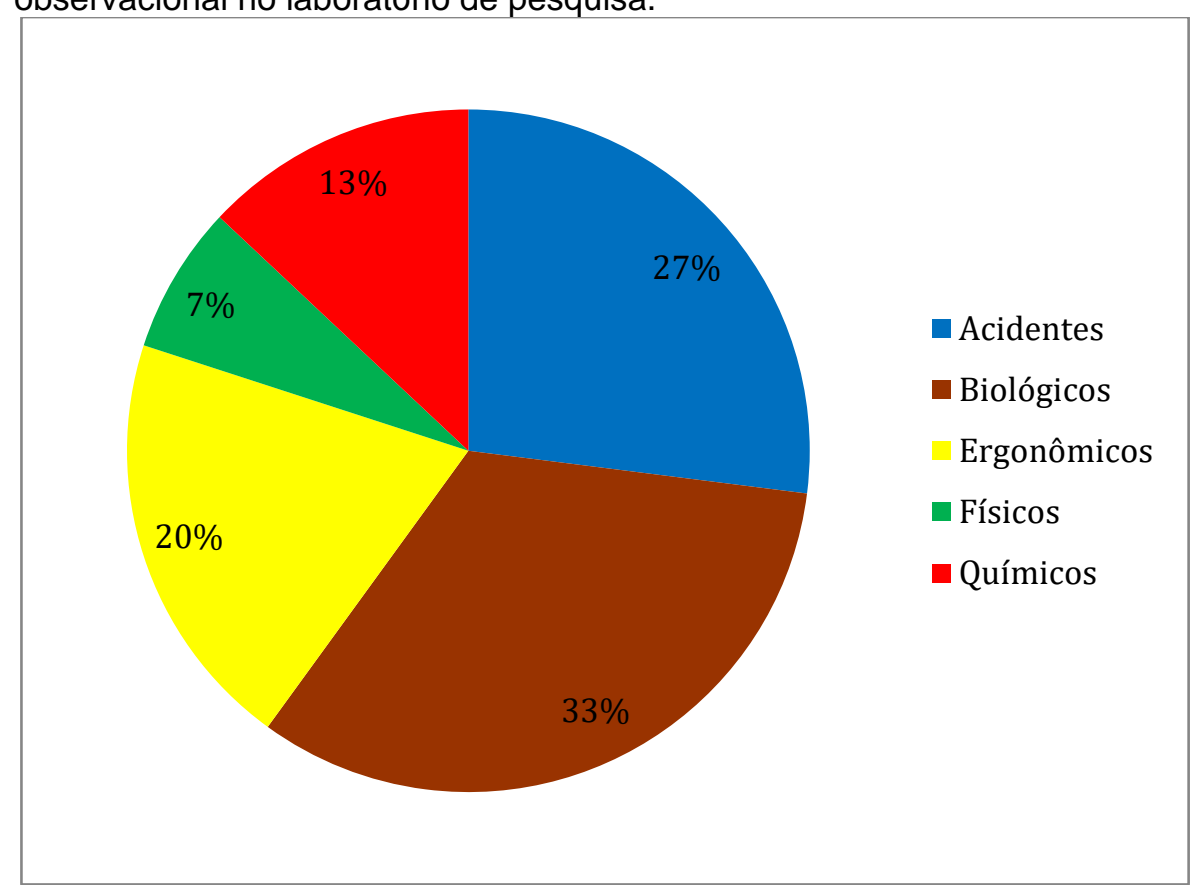

Fonte: Vicente JCS, et al., 2020. 


\section{Mapa de Risco}

No laboratório analisado há um mapa de risco, porém encontra-se na região externa deste local. Esse mapa se refere à instituição como um todo, não havendo um específico para cada laboratório. Não foram observadas a identificação e a sinalização de riscos por meio de cores no laboratório. Esse procedimento é importante, visto que serve para alertar ao trabalhador qual o risco encontrado naquele espaço e que o mesmo está sujeito.

Dessa forma, foi elaborado um mapa de risco de acordo com as observações realizadas durante o período de visitação (Figura 2). Nele constam a disposição dos riscos biológicos, físicos, químicos, ergonômicos e de acidentes presentes no laboratório, identificados através de cores e níveis de intensidade.

Figura 2 - Mapa de risco desenvolvido durante a análise observacional no laboratório de pesquisa.

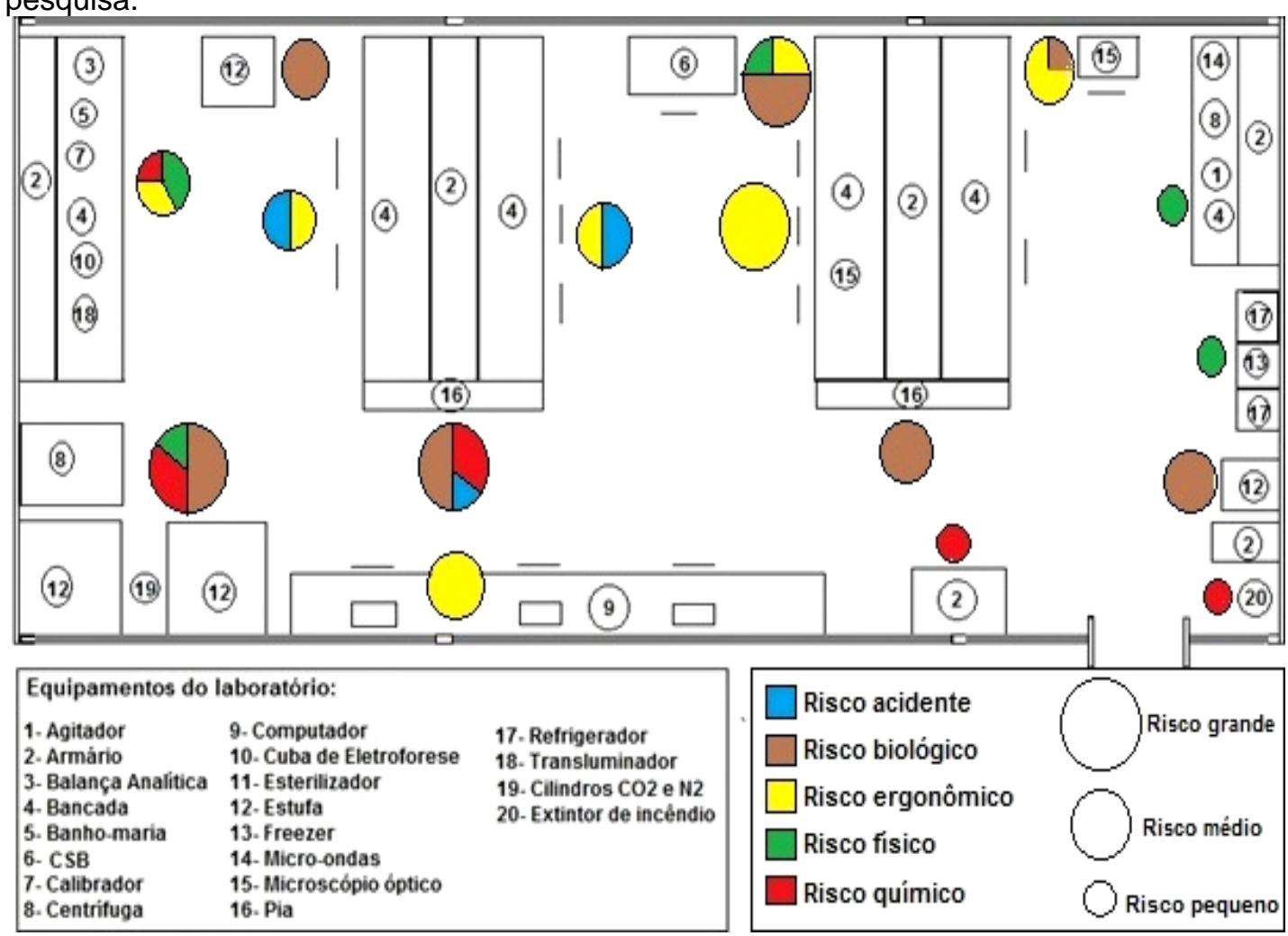

Fonte: Vicente JCS, et al., 2020.

Neste contexto, o mapa de risco sinaliza efetivamente os riscos presentes no laboratório, facilitando a sua identificação e localização. Desta maneira, gera um melhor entendimento para os usuários que frequentam este ambiente.

\section{CONCLUSÃO}

O presente estudo permitiu a avaliação dos riscos ambientais presentes em um laboratório de pesquisa. É válida a aplicação de ações e condutas corretivas a fim de minimizar os riscos, pois mesmo se tratando de um laboratório de ensino e pesquisa, há determinados riscos que podem prejudicar o dia a dia dos profissionais envolvidos. $O$ descarte realizado corretamente, a aplicação de boas práticas laboratoriais, a conscientização em utilizar EPI's específicos para cada atividade, a organização do ambiente e de cada experimento, assim como adotar medidas ergonômicas, pode melhorar o bem estar físico e mental do trabalhador. Este estudo permitiu a elaboração do mapa de risco, que conscientizará os membros desse laboratório e permitirá tanto uma maior qualidade nas atividades, quanto o estabelecimento de critérios. Desta maneira, serão possíveis a realização de práticas de biossegurança mais seguras e o reconhecimento dos riscos. 


\section{REFERÊNCIAS}

1. ANVISA, Agência Nacional de Vigilância Sanitária. Higienização das mãos em serviços de saúde. 2007. Brasília, 52 p.

2. ARAÚJO AP, et al. Análise da higienização das mãos pelos profissionais de saúde em ambiente hospitalar durante dois meses. Revista Saúde \& Ciência Online, 2015; 4(3): 44-54.

3. ARAÚJO EM, VASCONCELOS SD. Biossegurança em laboratórios universitários: um estudo de caso na Universidade Federal de Pernambuco. Revista Brasileira de Saúde Ocupacional, 2004; 29(110): 33-40.

4. AZEVEDO NA, et al. Avaliação dos riscos à saúde em ambiente ocupacional decorrentes da exposição a resíduos químicos. Revista Eletrônica do Prodema, 2016; 10(2): 120-132.

5. BARBOSA CM, et al. A importância dos procedimentos operacionais padrão (POPs) para os centros de pesquisa clínica. Revista da Associação Médica Brasileira, 2011; 57(2): 134-135.

6. BARBOSA EF, MOURA DG. Lista de verificação (Checklist) para planejamento e execução de Projetos. 2004. Minas Gerais, $6 \mathrm{p}$.

7. BRASIL, Fundação Nacional de Saúde. Diretrizes Para Projetos de Laboratórios de Análises de Água Para Consumo. Brasília: Funasa, 2012. 58 p.

8. BRASIL, Fundação Nacional de Saúde. Diretrizes para Projetos Físicos de Laboratórios de Saúde Pública. Brasília: Funasa, 2004. 84 p.

9. BRASIL, Instrução Normativa CTNBio nำ. Normas para o trabalho em contenção com organismos geneticamente modificados. Diário Oficial [da] União República Federativa do Brasil, Brasília, DF, 6 jun. 1997.

10. BRASIL, Norma Regulamentadora $n^{\circ} 8$ - Edificações. Portaria $n^{\circ} 3.214$ de 08 de junho de 1978. Diário Oficial [da] União República Federativa do Brasil. Ministério do Trabalho. Brasília, DF, 1978a.

11. BRASIL, Norma Regulamentadora no 9 - Programa de Prevenção de Riscos Ambientais (PPRA). Portaria no 3.214 , de 08 de junho de 1978. Diário Oficial [da] União República Federativa do Brasil. Ministério do Trabalho. Brasília, DF, 1978b.

12. BRASIL, Norma Regulamentadora o 17 - Ergonomia. Portaria n. 3.214 de 08 de junho de 1978. Diário Oficial [da] União República Federativa do Brasil. Ministério do Trabalho. Brasília, DF, 1978c.

13. BRASIL, Norma Regulamentadora no 32 - Segurança e Saúde no trabalho em serviços de saúde. Portaria n. 9485 de 16 de novembro de 2005. Diário Oficial [da] União República Federativa do Brasil. Ministério do Trabalho. Brasília, DF, 2005.

14. CHAVES MJF. Manual de Biossegurança e Boas Práticas Laboratoriais. 2016.

15. COLACO GA, et al. Avaliação de riscos ambientais, mecânicos e ergonômicos em um laboratório químico de uma Universidade Federal. In: XXXVI Encontro Nacional de engenharia de produção, João Pessoa, Paraíba, 2016; 14p.

16. FARIA VA, et al. Perigos e riscos na medicina laboratorial: identificação e avaliação. Jornal Brasileiro de Patologia e Medicina Laboratorial, 2011; 47(3): 241-247.

17. FERREIRA VMV, et al. Fisioterapia na avaliação e prevenção de riscos ergonômicos em trabalhadores de um setor financeiro. Fisioterapia e Pesquisa, 2009; 16(3): 239-245.

18. FRANKLIN SL, et al. Avaliação das condições ambientais no laboratório de anatomia patológica de um hospital universitário no município do Rio de Janeiro. Jornal Brasileiro de Patologia e Medicina Laboratorial, 2009; 45(6): 463470.

19. GOMES GCC. Métodos de Preparação Industrial de Solventes e Reagentes Químicos: Isopropanol (CAS 67-63-0). Revista Virtual de Química, 2016; 8(6): 2138-2146.

20. GOMES LC, et al. Biossegurança e resíduos de serviços de saúde no cotidiano acadêmico. Revista de Ciências Farmacêuticas Básica e Aplicada, 2014; 35(3): 443-450.

21. HINRICHSEN SL. Biossegurança e controle de infecção: risco sanitário hospitalar. Rio de Janeiro: MEDSI, 2004.835 p.

22. HINRICHSEN SL. Biossegurança e controle de infecção: risco sanitário hospitalar. Rio de Janeiro: Guanabara Koogan, 2018. $664 \mathrm{p}$.

23. KASSADA DS, et al. Ergonomia: Atividades que comprometem a saúde do trabalhador. In: VII Encontro Internacional de Produção Científica, 2011; 1-5.

24. OLIVEIRA CMA, et al. Guia do Laboratório para o Ensino de Química. Conselho Regional de Química- IV Região. Comissão de ensino técnico. São Paulo, 2007.

25. PENNA PMM, et al. Biossegurança: uma revisão. Arquivos do Instituto Biológico, 2010; 77(3): 555-565.

26. PEREIRA SSP, et al. Desinfecção com hipoclorito de sódio em superfícies ambientais hospitalares na redução de contaminação e prevenção de infecção: revisão sistemática. Revista da Escola de Enfermagem da USP, 2015; 49(4): $681-688$

27. RODRIGUES JA, et al. Avaliação de contaminação bacteriana de mobiliário de laboratório de microbiologia de uma universidade do Rio Grande do Sul. Revista Brasileira de Análises Clínicas, 2016; 48(1): 68-73.

28. ROSA FCS, et al. Biossegurança para Laboratórios de Ensino e Pesquisa. Vitória da Conquista, 2012,70 p.

29. SANGIONI LA, et al. Princípios de biossegurança aplicados aos laboratórios de ensino universitário de microbiologia e parasitologia. Ciência Rural, 2013; 43(1).

30. SILVA MDS, et al. Biossegurança em laboratórios: uma revisão de literatura. Revista Intertox de Toxicologia, Risco Ambiental e Sociedade, 2015; 8(2): 145-173.

31. VELOSO NETO H. Estratégias organizacionais de gestão e intervenção sobre riscos psicossociais do trabalho. International Journal On Working Conditions, p. 1-22, 2015.

32. VIEIRA RGL, et al. Riscos químicos e físicos em um laboratório de análises clínicas de uma Universidade. Medicina Ribeirão Preto, 2008; 4(41): 508-515.

33. ZOCHIO LB. Biossegurança em laboratórios de análises clínicas. Academia de Ciência e Tecnologia, São José do Rio Preto, 2009. 